\title{
Widening social inequalities in smoking cessation in Spain, 1987-1997
}

\author{
E Fernandez, A Schiaffino, M García, J M Borràs
}

In southern Europe, the prevalence of smoking among women has been lower than in northern Europe, with a wider gender and socioeconomic gap compared with most other developed countries. In Spain, a decline in the prevalence of smoking in men has been observed during the past 10 years, while in women the smoking prevalence has increased in the middle age group (16-44 years old) and in higher socioeconomic levels. Smoking cessation has increased slightly, ${ }^{1}$ but no assessment of the trends in smoking cessation in Spain by gender and socioeconomic level has been reported. The aim of this study was to analyse the pattern of smoking cessation according to gender and education, using data from the four National Health Interview Surveys (NHIS) conducted between 1987 and 1997.

\section{Methods}

Data were obtained from the Spanish NHISs conducted in 1987, 1993, 1995, and 1997 among the non-institutionalised population by means of personal interviews. Sample sizes of the surveys were 27756 subjects in 1987; 21120 in 1993; and 6400 both in 1995 and 1997. Non-response rates ranged from $10 \%$ in 1987 to $15 \%$ in 1997 . In the four surveys, a multistage random sampling strategy with stratification was used.

The same questionnaire was used in the 1993, 1995, and 1997 surveys, and the 1987 questionnaire presented only minor differences. Smoking habit was classified as current smokers (smoking daily), ex smokers (subjects who have smoked but currently do not smoke at all), and never smokers. We have classified people into four educational levels: less than primary studies, primary studies, secondary studies, and university studies.

Only people aged $\geqslant 16$ years old who were ever smokers (current or ex smokers) were included in this analysis: 9734 men and 4174 women in 1987; 6589 men and 2947 women in 1993; 2002 men and 1024 women in 1995; and 1999 men and 1074 women in 1997.

Quit ratios and 95\% confidence intervals (CI) were computed as proportions of quitting smoking (former smokers/ever smokers), for men and women separately, and according to educational level, with direct standardisation for age, based on the 1991 Spanish population. Stratified analyses by age groups $(<45, \geqslant 45$ years) were also performed.

As a summary measure for socioeconomic inequality, the relative index of inequality (RII) was obtained by means of logistic regression. Educational level categories were assigned a value between 0 and 1, which represents the relative position of the central subject of the class. The RII is the odds ratio obtained and it expresses the risk for those of the bottom of the educational hierarchy compared with those at the top. ${ }^{2}$ Sampling weights derived from the sample design were included in the analyses, using SPSS 9.0.

\section{Results}

In men, a statistically significant increase in the quit ratio between 1987 (26.5\%) and 1997
Institut Català

d'Oncologia,

L'Hospitalet,

Barcelona, Spain

Correspondence: $\mathrm{Dr}$ Fernandez, Institut Català d'Oncologia, Servei de Prevenció i Control del Càncer, Av Gran Via s/n Km 2,7, 08907 L'Hospitalet, Barcelona, Spain

(efernandez@ico.scs.es)

Accepted for publication 27 April 2001
Table 1 Age standardised quit ratios (and 95\% confidence intervals) by sex and educational level in Spain, $1987-1997$. Spanish National Health Interview Surveys, 1987, 1993, 1995, and 1997

\begin{tabular}{|c|c|c|c|c|c|c|c|c|}
\hline \multirow[b]{2}{*}{ Men } & \multicolumn{2}{|l|}{1987} & \multicolumn{2}{|l|}{1993} & \multicolumn{2}{|l|}{1995} & \multicolumn{2}{|l|}{1997} \\
\hline & $Q R^{*}$ & $(95 \% C I)$ & $Q R^{\star}$ & $(95 \% C I)$ & $Q R^{\star}$ & $(95 \% C I)$ & $Q R^{*}$ & $(95 \% C I)$ \\
\hline Total & 26.5 & $(25.7,27.3)$ & 32.8 & $(31.3,33.4)$ & 33.1 & $(31.3,35.0)$ & 34.1 & $(32.3,36.0)$ \\
\hline \multicolumn{9}{|l|}{ Level of education } \\
\hline Primary and Less than primary & 25.5 & $(24.6,26.5)$ & 30.6 & $(29.6,31.6)$ & 29.4 & $(27.7,32.0)$ & 30.9 & $(28.2,33.4)$ \\
\hline Secondary & 26.2 & $(23.7,28.6)$ & 31.7 & $(28.6,34.8)$ & 36.9 & $(31.9,41.9)$ & 36.4 & $(31.5,41.2)$ \\
\hline \multirow[t]{2}{*}{ University } & 29.1 & $(26.0,32.2)$ & 37.1 & $(34.2,40.0)$ & 34.9 & $(28.8,40.9)$ & 43.7 & $(37.3,50.2)$ \\
\hline & RIIt & $(95 \% C I)$ & RIIt & (95 CI) & RII & $(95 \% C I)$ & RII & $(95 \% C I)$ \\
\hline All ages & 1.68 & $(1.34,2.11)$ & 1.79 & $(1.40,2.28)$ & 2.11 & $(1.37,3.25)$ & 2.19 & $(1.42,3.36)$ \\
\hline $16-44$ years & 1.86 & $(1.40,2.47)$ & 2.14 & $(1.56,2.95)$ & 2.34 & $(1.33,4.11)$ & 3.05 & $(1.71,5.44)$ \\
\hline$\geqslant 45$ years & 1.12 & $(0.73,1.73)$ & 1.07 & $(0.71,1.63)$ & 1.58 & $(0.77,3.24)$ & 1.12 & $(0.54,2.32)$ \\
\hline Women & $Q R^{*}$ & $(95 \% C I)$ & $Q R^{\star}$ & $(95 C I)$ & $Q R^{*}$ & $(95 \% C I)$ & $Q R^{\star}$ & $(95 \% C I)$ \\
\hline Total & 31.3 & $(29.0,33.2)$ & 28.5 & $(26.4,30.7)$ & 25.8 & $(22.2,29.4)$ & 28.4 & $(25.0,31.9)$ \\
\hline \multicolumn{9}{|l|}{ Level of education } \\
\hline Primary and less than primary & 31.0 & $(29.1,34.0)$ & 27.0 & $(24.3,29.7)$ & 25.0 & $(20.4,29.5)$ & 26.7 & $(22.0,31.4)$ \\
\hline Secondary & 33.2 & $(27.0,39.3)$ & 28.6 & $(23.5,33.7)$ & 26.1 & $(18.0,34.2)$ & 28.9 & $(21.5,36.3)$ \\
\hline \multirow[t]{2}{*}{ University } & 32.6 & $(26.4,38.9)$ & 32.2 & $(26.8,37.6)$ & 29.5 & $(19.3,39.6)$ & 31.2 & $(23.8,38.6)$ \\
\hline & RII & $(95 \% C I)$ & RII + & (95 CI) & RII & $(95 \% C I)$ & RII & $(95 \% C I)$ \\
\hline All ages & 0.78 & $(0.56,1.05)$ & 1.68 & $(1.21,2.34)$ & 1.12 & $(0.64,2.00)$ & 1.68 & $(0.99,2.87)$ \\
\hline $16-44$ years & 0.59 & $(0.42,0.82)$ & 1.74 & $(1.21,2.49)$ & 1.15 & $(0.54,1.85)$ & 1.71 & $(0.94,3.11)$ \\
\hline$\geqslant 45$ years & 2.36 & $(0.85,6.51)$ & 1.51 & $(0.63,3.66)$ & 0.94 & $(0.18,4.95)$ & 1.67 & $(0.51,6.84)$ \\
\hline
\end{tabular}

${ }^{\star}$ Age standardised quit ratio (\%); †relative index of inequality (see text). 
$(34.1 \%)$ was observed. In the four surveys, the quit ratio among subjects with secondary and university studies was higher than that of subjects with lower level of education (table 1). Although smoking cessation has increased in all educational groups, the differences in cessation rates have widened, as shown by the increasing RIIs (table 1). These differences were more marked among subjects aged 16-44 years old.

In women, the quit ratio decreased between 1987 and 1997, especially among those in lower educational categories, with an increase in inequalities by educational level (RII of 0.78 in 1987 and of 1.68 in 1997). By age group, the quit ratio only increased among university women aged $<45$ years (from $15.7 \%$ in 1987 to $26.1 \%$ in $1997 ; \mathrm{p}<0.05)$, and a decrease was evident among women aged $\geqslant 45$ years old, though there was no clear pattern by educational level (table 1).

\section{Discussion}

The most important and most discouraging finding is the broadening gap of smoking cessation by educational level in men. Although the overall quit ratio has increased in men, the data show that it is more marked among the upper educational levels. In women, the only positive tendency was observed among those in higher educational categories and aged $<45$ years old, a tendency that is similar to that observed in men. The high smoking initiation rates among young women in our country ${ }^{3}$ might well explain why no overall increase in cessation is observed among women, although the possibility that fewer women had tried to quit, or that those who had tried were not successful cannot be disregarded. ${ }^{4}$

Why are educational inequalities in smoking cessation widening? Disadvantaged men and women are less likely to absorb messages about the effects of tobacco smoking on health. ${ }^{5}$ Furthermore, increasing taxation is the other strategy used to reduce tobacco consumption, and tends to have a greater impact among women and disadvantaged groups than health publicity. ${ }^{5}$ However, in Spain, tobacco is very cheap ${ }^{6}$ and increases in taxation of tobacco products did not begin until 1992, but no reduction in consumption is apparent as yet. ${ }^{7}$ High levels of cigarette smuggling (about 15\% of the total market in 1997) ${ }^{8}$ may also help to explain why Spain has one of the lowest declines in cigarette consumption in Europe. ${ }^{7}$

In conclusion, these data show a widening of the social inequalities in smoking cessation in men in Spain. Interventions aimed at promoting smoking cessation should also tackle the reduction of these inequalities. Moreover, it is necessary to adopt strategies that tackle not only the smoking habit of women and disadvantaged groups but also the social and economic factors that reinforce their habit.

The authors wish to thank the Directorate of Public Health of the Ministry of Health, for providing the data files from the Spanish National Health Interview Surveys. The authors are grateful to Dr John P Pierce and Dr Carme Borrell for their critiques of earlier versions of this paper.

Funding: this work was partially funded by the Fondo de Investiación Sanitaria (FIS) (Contract no 00/0695).

Conflicts of interest: none.

1 Ministerio de Sanidad y Consumo. Encuestas nacionales de Salud 1987, 1993, 1995 y 1997. Madrid: Ministerio de Sanidad y Consumo, 1990-1999.

2 Kunst AE, Mackenbach JP. Measuring socioeconomic inequalities in health. Copenhagen: WHO, Regional Office for Europe, 1994.

3 Borras JM, Fernandez E, Schiaffino A, et al. Pattern of smoking initiation in Catalonia (Spain) from 1948 to 1992 . Am $\mathcal{F}$ Public Health 2000;90:1459-62.

4 Jarvis MJ. Gender differences in smoking cessation: real or myth? Tobacco Control 1994;3:324-8.

5 Townsend J, Roderick P, Cooper J. Cigarette smoking by socioeconomic group, sex, and age: effects of price, income, socioeconomic group, sex, and age: effects of
and health publicity. BMF 1994;309:923-7.

6 Montes A, Villalbi TR. The price of cigarettes in the European Union. Tobacco Control 2001;10:135-6.

7 Franceschi S, Naett C. Trends in smoking in Europe. Eur 7 Cancer Prev 1995;4:271-84.

8 Joosens L, Raw M. How can cigarette smuggling be reduced? BMF 2000;321:947-50. 